\title{
Therapeutic potential of curcumin in diabetic retinopathy (Review)
}

\author{
JIAN YANG, XIAO MIAO, FENG-JUAN YANG, JIN-FENG CAO, \\ XIN LIU, JIN-LING FU and GUAN-FANG SU \\ Department of Ophthalmology, The Second Hospital of Jilin University, Changchun, Jilin 130041, P.R. China
}

Received July 27, 2020; Accepted February 11, 2021

DOI: $10.3892 / \mathrm{ijmm} .2021 .4908$

\begin{abstract}
Diabetic retinopathy (DR) is a type of retinal microangiopathy caused by diabetes mellitus. It has become the leading cause of blindness among working individuals worldwide. DR is becoming increasingly common among younger diabetic patients and there is a need for lifelong treatment. The pathogenic mechanisms of DR are influenced by a number of factors, such as hyperglycemia, hyperlipidemia, inflammatory response and oxidative stress, among others. Currently, the treatment
\end{abstract}

Correspondence to: Dr Guan-Fang $\mathrm{Su}$ or Dr Jin-Ling Fu, Department of Ophthalmology, The Second Hospital of Jilin University, 218 Ziqiang Street, Changchun, Jilin 130041, P.R. China E-mail: sugf2012@163.com

E-mail: fujinling1981@163.com

Abbreviations: DR, diabetic retinopathy; VEGF, vascular endothelial growth factor; DN, diabetic nephropathy; CVD, cardiovascular disease; COPD, chronic obstructive pulmonary disease; NPDR, non-proliferative DR; PDR, proliferative DR; GSH, glutathione; ROS, reactive oxygen species; ICAM-1, intercellular adhesion molecule-1; VCAM-1, vascular cell adhesion molecule-1; iNOS, inducible nitric oxide synthase IL, interleukin; TNF- $\alpha$, tumor necrosis factor $\alpha$; MCP-1, monocyte chemoattractant protein-1; $\mathrm{NF}-\kappa \mathrm{B}$, nuclear factor- $\kappa \mathrm{B}$; NO, nitric oxide; RPECs, retinal pigment epithelial cells; STZ, streptozotocin; ARPE-19 cells, adult retinal pigment epithelial cells; ER, endoplasmic reticulum; Nrf2, nuclear factor E2-related factor 2; DNMT, DNA methyltransferase; T-AOC, total antioxidant capacity; SOD, superoxide dismutase; LOX, lipoxygenase; XOD, xanthine oxidase; MDA, malondialdehyde; PKC, protein kinase C; MMP, matrix metalloproteinase; CRP, C-reactive protein; PPAR- $\gamma$, peroxisome proliferator-activated receptor- $\gamma$; p-Akt: phosphorylated Akt; SDF-1, stromal cell-derived factor-1; AP-1, activator protein-1; HO-1, heme oxygenase-1; AMPK, AMP-activated protein kinase; mTOR, mammalian target of rapamycin; JNK1, c-Jun N-terminal kinase; LC3, light chain 3; UVRAG, ultraviolet radiation resistance-associated gene protein; ATG5, autophagy-related protein 5; GLP-1, glucagon-like peptide-1; HDL-C, high-density lipoprotein cholesterol; LDL-C, low-density lipoprotein cholesterol

Key words: curcumin, diabetes mellitus, diabetic retinopathy, therapeutics methods for DR mainly include retinal photocoagulation, vitrectomy, or anti-vascular endothelial growth factor (VEGF) therapy. However, these methods have some disadvantages and limitations. Therefore, it is a matter of great interest and urgency to discover drugs that can target the pathogenesis of DR. Since ancient times, traditional Chinese medicine practitioners have accumulated extensive experiences in the use of Chinese herbal medicine for the prevention and treatment of diseases. In the theory of traditional Chinese medicine, curcumin has the effects of promoting blood circulation and relieving pain. A number of studies have also demonstrated that curcumin has multiple biological activities, including exerting anti-apoptotic, anti-inflammatory, antioxidant and antitumor properties. In recent years, studies have also confirmed that curcumin can prevent a variety of diabetic complications, including diabetic nephropathy (DN). However, the preventive and curative effects of curcumin on DR and its mechanisms of action have not yet been fully elucidated. The present review aimed to explore the therapeutic potential of curcumin in diabetes mellitus and DR.

\section{Contents}

1. Introduction

2. Composition, structure and functions of curcumin

3. Bioavailability of curcumin and methods with which it can be improved

4. Therapeutic effect of curcumin on diabetes

5. Protective effects of curcumin on DR

6. Conclusions

\section{Introduction}

Diabetes mellitus, a disease affecting individuals worldwide with a complex course and a number of complications, has garnered increasing attention. The International Diabetes Federation predicts that the number of adults aged 20-79 years with diabetes mellitus globally will increase to 700 million by 2045 , and 3 out of 4 individuals will be of working age (1). The incidence of this disease is influenced by a number of factors, such as body mass index, body fat distribution, metabolic syndrome and sex differences (2-4). Even sleep deprivation and work-related stress can influence its incidence $(5,6)$. The 
complications of diabetes mellitus can be classified into macrovascular complications [for example, cardiovascular disease (CVD)] and microvascular complications (for example, complications affecting the retina, kidneys and the nervous systems). Diabetic retinopathy (DR) is closely related to hyperglycemia caused by diabetes mellitus. Traditionally, DR was considered to be a microvascular disease; however, new research has found that retinal neurodegeneration is also closely related to its occurrence (7). Thus, the pathogenic mechanisms underlying DR are very complex.

Curcumin represents the major constituent of turmeric. In addition to being widely recognized as a spice, curcumin also has a variety of therapeutic effects. For example, as an anticancer agent, it can prevent ovarian, prostate, breast and gastric cancers (8-11). Moreover, curcumin exerts anti-inflammatory effects, and it can be used in the treatment of chronic obstructive pulmonary disease (COPD), hepatic inflammation and even acute vascular inflammation (12-14). As a natural antioxidant, the reno-protective effects of curcumin have been demonstrated (15). In diabetic rats and Müller cells, the increase in histone acetylation plays an important role in the regulation of the inflammatory response. Curcumin can exert protective effects on diabetes by inhibiting histone acetylation (16-18). The preventive and curative effects of curcumin on DR and its mechanisms of action have, however, not been thoroughly defined. The present review article aimed to investigate the therapeutic effects of curcumin on diabetes mellitus and DR, and to demonstrate the possible mechanisms through which it exerts these effects.

\section{Composition, structure and functions of curcumin}

Curcuma is a perennial herbaceous plant with developed rhizomes that belongs to the order Zingiberaceae. It is mainly grown in India and China. It was first known for its role as a food additive or spice in cooking (e.g., curry). Curcumin, the main component of Curcuma (Fig. 1) (19), has important health benefits. In the theory of traditional Chinese medicine, curcumin relieves pain. It can be used in the treatment of abdominal distention, arm pain, fall injury, amenorrhea and other diseases. In modern medical research, the phenolic substances extracted from the rhizome of Curcuma longa (Fig. 2) exert a wide range of protective effects against diabetes-related metabolic disorders and play an important role in reducing blood lipid levels. They also have antioxidant, anti-inflammatory and antitumor properties $(20,21)$. Other advantages of curcumin include its affordability, safety and ease of extraction. Currently, a number of methods have been adopted to enhance the bioavailability of curcumin, such as combining it with appropriate pharmaceutical excipients, synthesizing curcumin analogs, or changing dosage forms. As a drug, curcumin has good therapeutic prospects.

\section{Bioavailability of curcumin and methods with which it can be improved}

The low bioavailability of curcumin may be related to the low solubility of curcumin, the poor permeability of the gastrointestinal mucosa and the rapid clearance of curcumin in vivo. Although curcumin exerts therapeutic effects against diabetes and related diseases, data from clinical trials have demonstrated that even when a large dose $(12,000 \mathrm{mg} / \mathrm{day})$ of curcumin is used in the treatment of the human body, the curcumin content in the serum remains low (22). Further research has also indicated that the use of dendritic nanoparticles can enhance the solubility of curcumin in vivo (23) and improve the bioavailability of curcumin. In an in vitro study, scholars have found that solid lipid nanoparticles loaded with curcumin can prolong the release time of curcumin in vitro to $12 \mathrm{~h}$ with good stability (24). Furthermore, in an in vivo experiment in rats with asthma, the use of curcumin lipid nanocarriers has also been found to increase the concentration of curcumin in plasma suspension and tissue (25). In addition, it has been found that the administration of piperine within $1 \mathrm{~h}$ following the curcumin administration can significantly increase the serum concentration of curcumin in rats and humans, enhance its bioavailability, and exerts no side-effects (26). As a therapeutic drug, curcumin has other structural analogs that can enhance its therapeutic effect. Compared with curcumin, its structural analog EF24 has significant activity in the treatment of leukemia (27). The above-mentioned methods can enhance the bioavailability of curcumin to enhance its therapeutic effect.

\section{Therapeutic effect of curcumin on diabetes}

Diabetes represents a group of metabolic diseases. Over the past decades, its incidence has increased exponentially (28), and as a chronic disease that can cause damage to a variety of organs, the prevention and treatment of diabetes have garnered increasing attention. Studies have indicated that curcumin can protect diabetic patients or cultured cells in vitro (29). In terms of prevention, it has been found that curcumin can significantly reduce the number of patients who eventually progress to type 2 diabetes after 9 months of curcumin intervention at the pre-diabetic stage. In addition, curcumin treatment has been shown to improve the overall function of $\beta$ cells (30). Al-Saud found that curcumin treatment exerted hypoglycemic effects in rats with diabetes induced by a high-fat diet combined with a streptozotocin (STZ) injection; furthermore, curcumin reduced insulin resistance in tissues and improved the diabetic status (31).

Similarly, some scholars have found that curcumin can significantly reduce fasting blood glucose in diabetic rats. In rats treated with curcumin, pancreatic tissue damage has been shown to be mild, and the expression levels of interleukin (IL)-1, IL-6, monocyte chemoattractant protein-1 (MCP-1), tumor necrosis factor (TNF)- $\alpha$, Bax and caspase- 3 have been found to be significantly reduced. These results indicate that curcumin can curb pancreatic islet cell apoptosis and inflammation, all the while promoting the recovery of pancreatic function $(32,33)$.

Curcumin also plays an important protective role in cells under high-glucose conditions in in vitro experiments $(34,35)$. In a study that exposed insulin (INS)-1 cells to high glucose with or without curcumin, the proliferation of INS-1 cells, the morphological changes of islet cells, the production of reactive oxygen species (ROS) as well as the activities of superoxide dismutase and catalase, insulin levels, the expression of nicotinamide adenine dinucleotide phosphate 


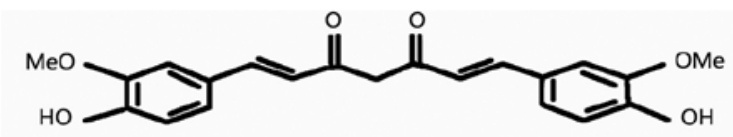

Formula [1,7-bis-(4-hydroxy-3-methoxyphenyl)-1,6-heptadiene-3,5-dione]

Figure 1. Chemical structure of curcumin.

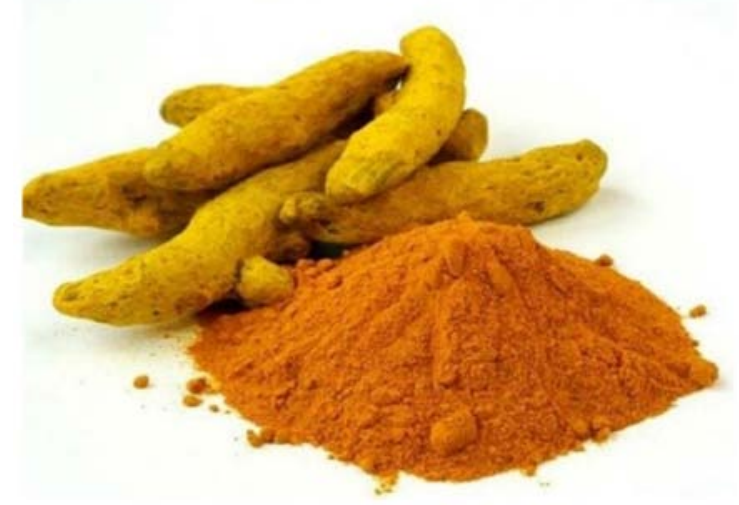

Figure 2. Rhizomes of Curcuma longa and powdered turmeric.

(NADPH) oxidase subunits, and the expression of apoptotic factors were observed (34). The results of that study revealed that curcumin effectively inhibited the proliferation-induced damage and oxidative stress caused by high glucose in INS-1 cells, increased the insulin level, and reduced the expression of NADPH oxidase subunits and apoptotic factors. These results also suggested that curcumin alleviated high-glucose/palmitate-induced oxidative stress in islet cells by regulating the NADPH pathway and protected islet cells from apoptosis (34). $\mathrm{Xia}$ et al found that following curcumin administration, the activity of rat insulinoma RIN-m5F $\beta$-cells increased, the apoptotic rate of the cells decreased and the cells were protected (35). These results indicate that curcumin protects islet cells from the damaging effects of high glucose through anti-inflammatory and anti-apoptotic pathways, and it can play a certain therapeutic role in diabetes by directly reducing blood glucose levels.

\section{Protective effects of curcumin on DR}

Antioxidant effects of curcumin. Oxidative stress plays a key role in diabetic microvascular complications. Under abnormal metabolic conditions created by diabetes, superoxide production in microvascular endothelial cells and the mitochondria is increased. Since glutathione (GSH) is one of the important scavengers of ROS, a reduced expression of NADPH, which is required to generate $\mathrm{GSH}$, is consumed excessively under a high glucose state, eventually leading to an increased ROS generation. Increased intracellular ROS levels, aggravated by oxidative stress and accompanied by an increased local inflammatory response, ultimately lead to the apoptosis of endothelial cells and pericytes $(36,37)$. Under this premise, the barrier function of the tight junctions of retinal capillary epithelial cells is disrupted, leading to the leakage of intraretinal fluid. Kowluru and Kanwar demonstrated that in the diabetic rat retina, the level of oxidation-modified DNA in the cells continued to increase (38). Moreover, compared to that in the age-matched normal control group, the antioxidant capacity of the retina of diabetic rats decreased by approximately $30-35 \%$. Curcumin may not only reduce the level of oxidative stress, but may also inhibit the increase in the retinal nitrotyrosine level, effectively reducing retinal damage caused by the accumulation of nitrotyrosine in the retina (38). A schematic diagram of the effects of curcumin on oxidative stress effects is depicted in Fig. 3. Some scholars have indicated that the combination of curcumin and oral anti-diabetic drugs or other natural antioxidants exerts a more beneficial effect on the treatment of diabetes and its complications compared with the use of a single drug $(39,40)$. As a regulator of antioxidant reduction, nuclear factor E2-related factor 2 (Nrf2) plays an important anti-DR role in the diabetic state. Curcumin can increase the Nrf2 level, thus promoting its anti-fibrotic effect (41). In Müller cells of rats with STZ-induced DR, curcumin has been shown to reduce the level of malondialdehyde (MDA) in the retina and increase the level of glutathione (GSH), thereby inhibiting oxidative stress in diabetic retina and protecting Müller cells (42). ROS are normal products of cell metabolism which can be leveraged as regulators of cell signal transduction. However, high levels of ROS may exert cytotoxic and mutagenic effects on cells, resulting in the destruction of lipids, proteins, DNA and carbohydrates, and finally leading to cell apoptosis (43). In DR, oxidative stress increases with the progression of the disease. Curcumin can mitigate oxidative stress by scavenging various forms of free radicals, including ROS and reactive nitrogen species. In a previous study, curcumin restored the expression and function of DNA methyltransferase (DNMT) and inhibited oxidative stress and ROS in cultured ARPE-19 cells (44). In addition, it can inhibit protein kinase $\mathrm{C}$ (PKC) and other enzymes, such as lipoxygenase (LOX) and xanthine oxidase (XOD), which can produce ROS $(45,46)$. As a key molecule in oxidative stress, PKC plays a role in the pathogenesis of DR. Some scholars have found that curcumin can inhibit PKC to a certain extent, reduce the degree of oxidative stress, and thus exert a protective effect with regard to retinal tissue (47). The total antioxidant capacity (T-AOC) can reflect the antioxidant capacity of an organism. Yang et al found that in a rat model of STZ-induced DR, curcumin lowered the level of MDA and significantly increased the level of superoxide dismutase (SOD) in rat retinal tissue after 16 weeks of treatment (48). In parallel, the activity of T-AOC also significantly increased (48). In addition, Bulboacă et al found that curcumin significantly reduced the levels of total oxidative stress and catalase in diabetic rats (49). In short, curcumin can downregulate the level of ROS and reduce the apoptosis of endothelial cells by increasing the levels of antioxidant stress substances and reducing the levels of ROS related enzymes. Thus, curcumin plays an important antioxidant role in DR.

Anti-inflammatory effects of curcumin. The occurrence and progression of DR are closely related to inflammation (50). Some scholars have demonstrated that the pathogenesis of DR is similar to that of chronic inflammation, and in the retina and vitreous of diabetic patients and animals, the level of pro-inflammatory cytokines increases (51-53). 


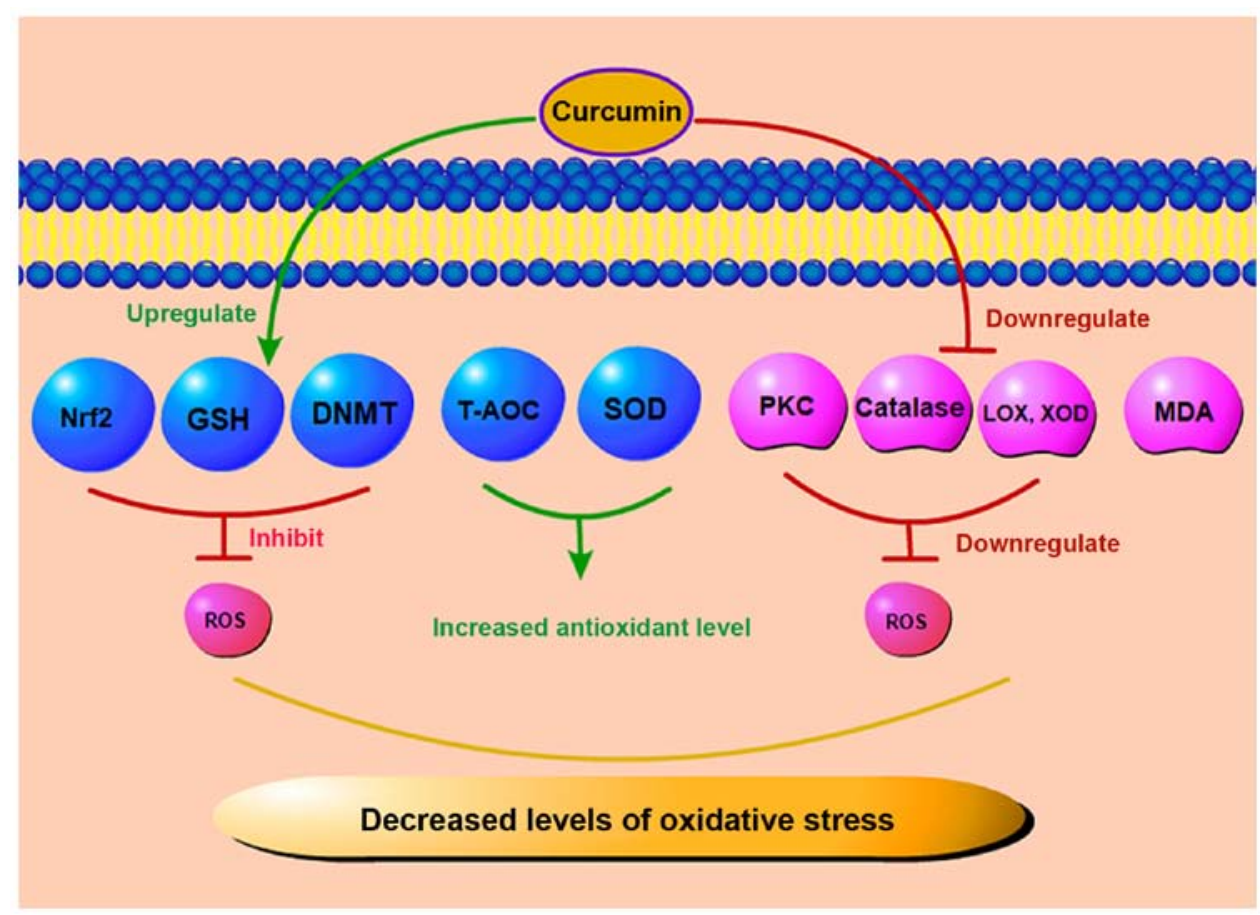

Figure 3. Antioxidant stress effects of curcumin. Curcumin increases the antioxidant capacity by increasing the Nrf2, DNMT and GSH levels, and by upregulating T-AOC and SOD expression. Curcumin may also reduce the levels of LOX, XOD, PKC and catalase, and downregulate the MDA levels to decrease the level of oxidative stress. Nrf2, nuclear factor E2-related factor 2; DNMT, DNA methyltransferase; GSH, glutathione; T-AOC, total antioxidant capacity; SOD, superoxide dismutase; LOX, lipoxygenase; XOD, xanthine oxidase; MDA, malondialdehyde; PKC, protein kinase C; ROS, reactive oxygen species.

The activation of retinal Müller cells may play a critical role in the early development of inflammation, which is the late cause of retinal damage. During the early pathological process of DR, the levels of intercellular adhesion molecule-1 (ICAM-1) and vascular cell adhesion molecule-1 (VCAM-1) increase (54). In addition, a number of inflammatory cytokines, such as IL- $1 \beta$, IL- 6 , IL- 8, TNF- $\alpha$ and $\mathrm{MCP}-1$, are present in eye tissues in non-proliferative DR (NPDR), and their expression levels are increased (55). DR development is accompanied by ROS levels, which can further activate nuclear factor- $\kappa \mathrm{B}(\mathrm{NF}-\kappa \mathrm{B})$, thereby increasing the levels of pro-inflammatory mediators, such as cytokines (IL-6) $(56,57)$. The levels of IL-1 $\beta$ and IL-6 are increased in retinal pigment epithelial cells (RPECs) that are treated with high glucose. In response to IL-1 stimulation, ROS and NF- $\kappa \mathrm{B}$ levels may be released, further increasing the production of pro-inflammatory mediators and forming a mutually reinforcing feedback mechanism. It has also been indicated that oxidative stress and inflammation interact and jointly mediate the occurrence and development of DR (58). TNF- $\alpha$ can act on vascular endothelial cells, damaging them, leading to cell hypoxia and necrosis. Moreover, as an inflammatory cytokine, TNF- $\alpha$ is closely related to insulin resistance and chronic inflammation. Costagliola et al found that in the tears of patients with type 2 diabetes, the level of TNF- $\alpha$ was significantly increased in patients with DR, particularly in proliferative diabetic retinopathy (PDR) (59). In rats with STZ-induced diabetes, the level of TNF- $\alpha$ was also increased. When curcumin was used, the TNF- $\alpha$ levels in the group that was administered curcumin were reduced by 2.5 -fold compared with those in the diabetes group; this was accompanied by a resolution of the basement membrane layer edema (60). A schematic diagram of the anti-inflammatory effects of curcumin is presented in Fig. 4.

Peroxisome proliferator-activated receptor- $\gamma$ (PPAR- $\gamma$ ), a receptor activated by peroxisome proliferators, is a transcription factor induced by ligands. In peripheral monocytes, PPAR $-\gamma$ is induced in the process of infiltration of blood vessels into tissues and the activation of pro-inflammatory stimulation. Some scholars also believe that PPAR- $\gamma$ and its agonist not only improve glucose homeostasis, but also regulate inflammation $(61,62)$. In currently existing animal research models, PPAR- $\gamma$ agonists can inhibit the formation of retinal leukocytes and the leakage of retinal barrier in rats with STZ-induced DR, alongside reducing the levels of various inflammatory markers, such as MCP-1, IL-6, matrix metalloproteinase-9 (MMP-9), C-reactive protein (CRP), etc. $(63,64)$. Curcumin activates PPAR- $\gamma$, reduces the level of inflammatory factors in the peripheral blood of patients with type 2 diabetes and elevates the total antioxidant capacity (65). In addition, curcumin can also play a protective role in improving the activity of PPAR $-\gamma$ to reduce the production of nitric oxide (NO) and inhibit the proliferation of vascular smooth muscle cells and inflammatory reaction (66). Curcumin inhibits the expression of related cytokines by enhancing PPAR- $\gamma$ activity to reduce the stimulation of ROS and NF- $\kappa$ B and subsequently, inhibits inflammation and oxidative stress. It can also play an anti-inflammatory role by directly reducing the levels of the inflammatory factor, TNF- $\alpha$, and the damage to retinal cells in a high glucose state.

Anti-angiogenetic effects of curcumin. In DR, the levels of STAT3 can be upregulated by the pro-inflammatory factor, IL-6. Furthermore, its own activation can induce the 


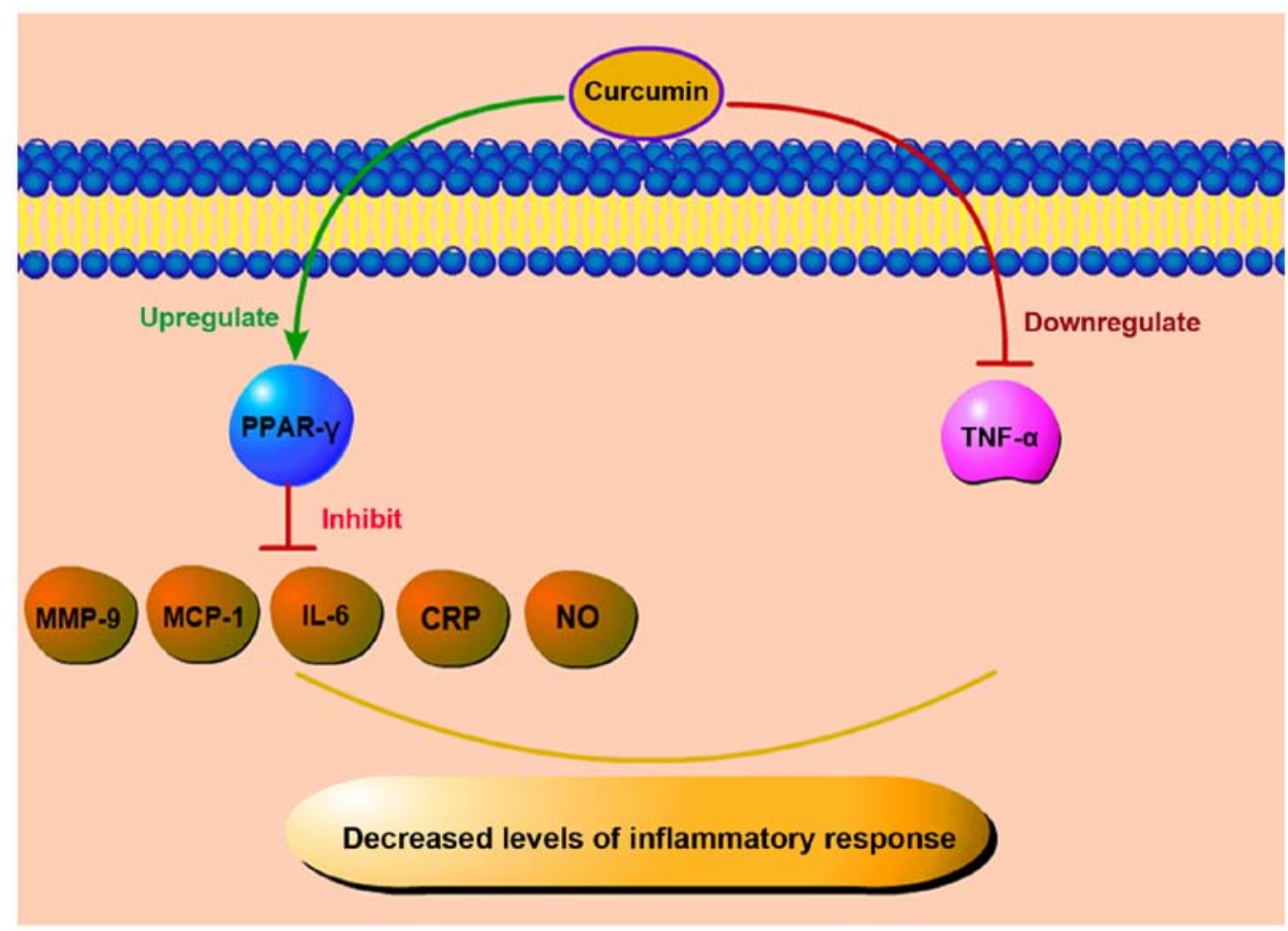

Figure 4. Anti-inflammatory effects of curcumin. Curcumin controls inflammatory responses by reducing inflammatory factors, such as MCP-1, IL-6, MMP-9, NO, and CRP, upregulating the level of PPAR- $\gamma$, and downregulating TNF- $\alpha$. MCP-1, monocyte chemoattractant protein-1; IL-6, interleukin-6; MMP-9, matrix metalloproteinase 9; CRP, C-reactive protein; NO, Nitric oxide; PPAR- $\gamma$, peroxisome proliferators-activated receptor- $\gamma$; TNF- $\alpha$, tumor necrosis factor $\alpha$.

production of VEGF and increase the permeability of endothelial cells, as well as pathological angiogenesis in retinal endothelial cells (67). On the one hand, it can be stated that while pro-inflammatory cytokines in diabetes may lead to retinal inflammatory injury, resulting in an altered retinal permeability, on the other hand, they may also indirectly result in pathological angiogenesis, causing greater damage to the eye.

VEGF represents another key factor involved in DR. Under physiological conditions, VEGF is a key factor involved in angiogenesis (68). In the DR state, VEGF is associated with the breakdown of the blood-retinal barrier. With the release of VEGF, the level of ICAM-1 increases (53), which further promotes the adhesion of leukocytes to retinal blood vessels and ultimately mediates retinal barrier breakdown and leakage, and retinal edema (69). With the increase in capillary occlusion, the state of retinal ischemia becomes more severe, leading to increased levels of VEGF, which in turn promote pathological neovascularization. The new vessels thus formed are very fragile, and their abnormal structure often leads to bleeding. The resulting progressive hemorrhage can further increase the expression of VEGF and aggravate chronic inflammatory response.

It is worth noting that diabetic rats treated with curcumin exhibit a significantly reduced VEGF expression. In a previous study, following treatment with curcumin, a significant reduction in the thickness of the retinal capillary basement membrane was observed in diabetic rats treated with curcumin, but not in the untreated diabetic rats (70). Some scholars have confirmed that curcumin can reduce the expression of VEGF, inducible nitric oxide synthase (iNOS) and ICAM-1 by inhibiting the activation of $\mathrm{CaMKII} / \mathrm{NF}-\kappa \mathrm{B}$ signaling in the diabetic rat retina and in Müller cells cultured in high glucose $(71,72)$. Curcumin not only exerts anti-VEGF effects on the retina, but also exerts anti-angiogenetic effects on the choroidal vascular system of diabetic rats. In another study, following treatment with curcumin, the size of blood vessels significantly increased, while both the degree of tortuosity of the diabetic microvascular system and the amount of generated microaneurysms decreased (73).

Some scholars have found that when the expression of phosphorylated-Akt (p-Akt) is downregulated, the angiogenesis of human umbilical vein endothelial cells (HUVEC) in vitro is also inhibited (74). It has been suggested that Akt phosphorylation may represent a key factor in angiogenesis. However, in RPECs that were treated with high glucose, curcumin was shown to reduce Akt phosphorylation and thus play a therapeutic role $(75,76)$. Okamoto et al demonstrated that the activation of $\mathrm{NF}-\kappa \mathrm{B}$ and activator protein-1 (AP-1) can contribute to age-induced angiogenesis through the overproduction of autocrine VEGF; however, curcumin, which is an inhibitor of $\mathrm{NF}-\kappa \mathrm{B}$ and $\mathrm{AP}-1$, can prevent the upregulation of VEGF mRNA and the subsequent increase of DNA synthesis in endothelial cells (77). Stromal cell-derived factor-1 (SDF-1) is another important factor in angiogenesis. The level of SDF-1 is increased whether in patients with PDR or endothelial cells cultured in high glucose in vitro $(78,79)$. Curcumin can significantly inhibit the SDF-1-induced migration of human retinal endothelial cells $(80,81)$. In summary, it is suggested that curcumin may play a therapeutic role in DR by reducing the level of SDF-1 and angiogenesis (Fig. 5). Studies have found that inflammation is involved in the 


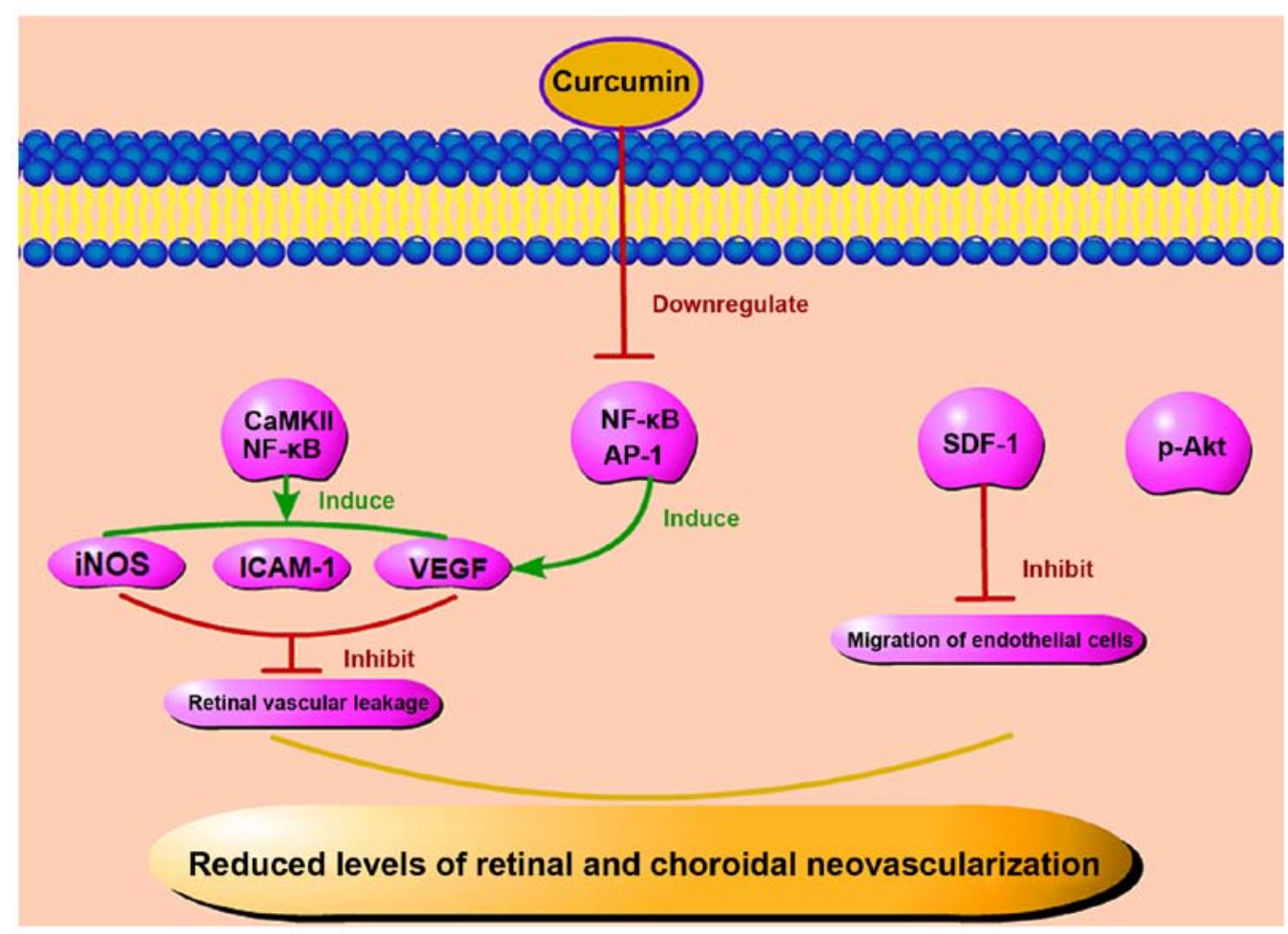

Figure 5. Anti-angiogenetic effects of curcumin. Curcumin can reduce angiogenesis by reducing the level of p-Akt. It also inhibits retinal and choroidal neovascularization by reducing the levels of SDF-1, NF- $\mathrm{BB}, \mathrm{AP}-1$, VEGF, iNOS and ICAM-1, thus preventing the migration of endothelial cells and retinal

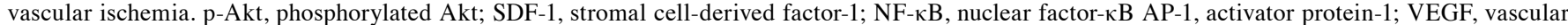
endothelial growth factor; ICAM-1, intercellular adhesion molecule-1; iNOS, inducible nitric oxide synthase.

process of angiogenesis. In mice, the subcutaneous injection of IL-1 $\alpha$ can induce a strong local angiogenic response, and VEGF receptor 2 (VEGFR-2)-neutralizing antibody can block the angiogenic effects of IL- $1 \alpha$. Therefore, pro-inflammatory factors can induce angiogenesis by activating the VEGF signaling pathway between inflammatory cells and vascular endothelial cells in a concentration-dependent manner (82). Curcumin not only directly inhibits abnormal angiogenesis, but may also rely on the regulation of inflammatory factors to reduce the level of inflammation, to further reduce the number of new blood vessels. On the whole, curcumin not only reduces the severity of DR through anti-inflammatory effects, but also regulates the number of abnormal retinal neovascularization events, reduces bleeding of pathological vessels, and further protects retinal tissue through anti-angiogenic mechanisms.

Anti-apoptotic and pro-autophagic effects of curcumin. Apoptosis or autophagy is a self-protective mechanism through which eukaryotic cells degrade toxic substances or damaged organelles through lysosomes. In the high glucose state, the expression of MMP-2 increases, while the expression of heat shock protein 60 and connexin 43 decreases, leading to mitochondrial membrane degradation, increased apoptosis, and more severe DR $(83,84)$. On the basis of in vitro and in vivo experiments, researchers have demonstrated that in retinal ganglion cells of mice with STZ-induced diabetes, the expression of caspase-3 gradually increases (85). In addition, as previously demonstrated, the apoptosis of adult retinal pigment epithelial cells (ARPE-19 cells) that were cultured under high glucose conditions also significantly increased (86).
These results indicate that increased apoptosis is also one of the key pathological mechanisms in diabetes.

Dysfunctional autophagy is associated with cancer, neurodegeneration, microbial infection and aging (87-90). Some scholars have shown that autophagy-related markers are increased in Müller cells cultured in vitro when exposed to a high glucose environment (91). In a high glucose environment, the inhibition of autophagy can lead to a higher apoptotic rate of Müller cells, while rapamycin, an autophagy inducer, can prevent the release of VEGF and prevent apoptosis. It is suggested that the promotion of autophagy may protect cells cultured in high glucose (92). Another explanation that has been proposed for the association between apoptosis, autophagy and DR is endoplasmic reticulum (ER) stress. ER stress is involved in cellular metabolism in physiological or pathological states. When ER stress remains mild, it helps cells adapt to an abnormal state; however, long-term, severe ER stress, which occurs in the diabetic state, can lead to increased autophagy and apoptosis (93).

Curcumin also plays an important role in anti-apoptosis and pro-autophagy (Fig. 6). As previously demonstrated, in cultured ARPE-19 cells subjected to high glucose in vitro, Hoechst staining revealed that the apoptotic rate of the cells increased in the high glucose state, while curcumin treatment reduced the abnormally increased apoptotic rate. This protection may induce the expression of heme oxygenase-1 (HO-1) through Nrf2 activation. Thus, curcumin plays a role in combating cell injury caused by high glucose $(94,95)$. In another group of animal experiments, Yang et al used a combination of low-dose STZ and a high-fat diet to establish 


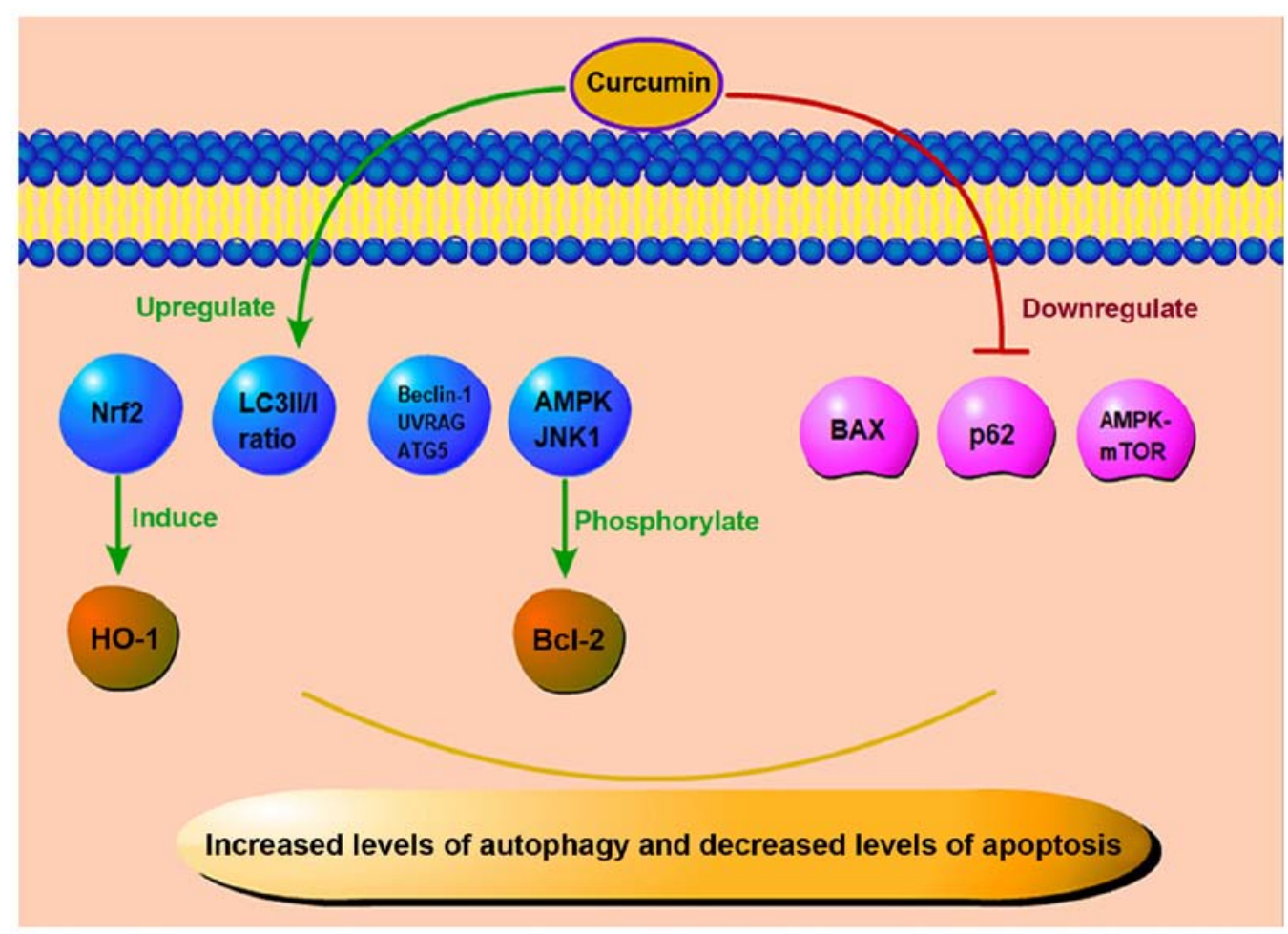

Figure 6. Anti-apoptotic and pro-autophagic effects of curcumin. Curcumin can upregulate the level of Nrf2 to induce the expression of HO-1, and it also plays an anti-apoptotic role by downregulating the levels of BAX, p62, and AMPK-mTOR, and phosphorylating Bcl-2 through AMPK and JNK1 pathways. In addition, curcumin can increase the ratio of LC3II/I and the level of Beclin-1. This way, curcumin can enhance autophagy and protect cells from further damage. Nrf2, nuclear factor E2-related factor 2; HO-1, heme oxygenase-1; AMPK, AMP-activated protein kinase; mTOR, mammalian target of rapamycin; JNK1, c-Jun N-terminal kinase; LC3, light chain 3; UVRAG, ultraviolet radiation resistance-associated gene protein; ATG5, autophagy-related protein 5.

an experimental rat model of diabetes (48). The experimental group was treated with curcumin every day. After 4 months of administration, the rats were euthanized, and their eyes were dissected. The expression of Bcl-2 and Bax in the retina was assessed by western blot analysis and immunohistochemistry. Compared with the control group, Bax expression in the retinae of rats in the experimental group was downregulated, and Bcl-2 expression was significantly increased. This suggested that curcumin played a role in inhibiting apoptosis, and can therefore exert a protective effect against DR (48).

Curcumin can also reduce insulin resistance in the diabetic state, and it has been proven to induce autophagy in gastric cancer cells. This effect is ROS concentration-dependent, suggesting that the control of ER stress by curcumin may be achieved by regulating the ROS level (96). Some scholars have found that curcumin can inhibit ER stress in HUVECs and enhance autophagy, which may maintain ER homeostasis by degrading denatured and damaged proteins (97). In a previous study, in mice with STZ-induced diabetic nephropathy (DN), following 8 weeks of treatment with curcumin, compared with the control group, the curcumin group had a significantly increased light chain 3 (LC3) II/I ratio, and the levels of autophagy-related proteins Beclin-1, ultraviolet radiation resistance-associated gene protein (UVRAG) and autophagy-related protein 5 (ATG5) were also increased. In the same vein, curcumin reduced the expression of p62 and enhanced the autophagy of podocytes in a high-glucose culture, thus exerting a protective effect on cells (98). Yao et al found that in mice with diabetic cardiomyopathy induced by a high-fat diet combined with a low-dose STZ injection, the apoptosis of cardiac cells increased, and autophagy was inhibited (99). Curcumin phosphorylated $\mathrm{Bcl}-2$ by activating the AMP-activated protein kinase (AMPK) and c-Jun N-terminal kinase-1 (JNK1) pathways, and then destroyed their interaction with Beclin-1; the AMPK-mammalian target of rapamycin (mTOR) pathway was also inhibited; both these effects ultimately promoted autophagy and reduced apoptosis, thus the protecting cells (99). Therefore, it can be hypothesized that the protective effects of curcumin on DR involve the reduction of abnormal apoptosis of the retinal tissue in a high-glucose state by regulating the level of apoptosis-related proteins. On the contrary, by properly enhancing autophagy and removing denatured and damaged proteins, curcumin can reduce the damage to the retinal barrier and the state of vascular leakage. In parallel, it can restore the normal level of apoptosis and reduce the damage to the retina caused by high glucose.

Anti-hyperglycemic and anti-hyperlipidemic effects of curcumin. Hyperglycemia has been inevitably implicated as the main cause of DR. In addition to increasing the production of ROS through the autoxidation of glucose in a hyperglycemic environment, oxidative stress is also associated with hyperglycemia-induced metabolic pathways in DR. With an increase in the glucose concentration, $\mathrm{NF}-\kappa \mathrm{B}$, one of the key mediators of pro-inflammation, is also constantly activated. Moreover, high glucose levels can induce the oxidative stress pathway, promote the production of multiple free radicals and participate in the pathogenic mechanisms of DR (100). 


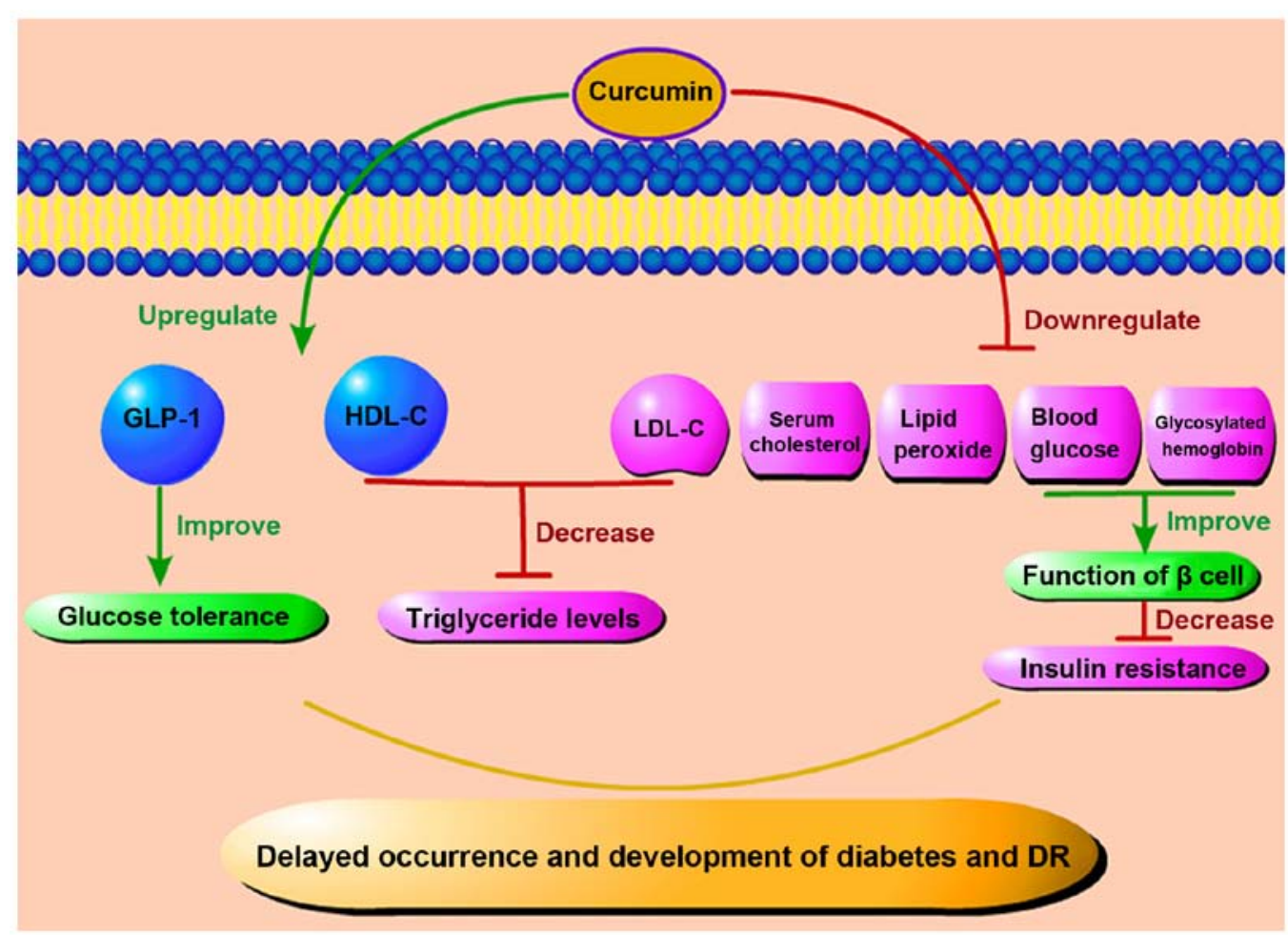

Figure 7. Anti-hyperglycemic and anti-hyperlipidemic effects of curcumin. Curcumin can enhance the level of GLP-1 to improve glucose tolerance and reduce triglycerides by regulating the level of lipoproteins. It can also control insulin resistance by lowering blood glucose and glycosylated hemoglobin levels. These effects can ultimately delay the progression of diabetes and DR by down-regulating serum cholesterol and lipid peroxides. DR, diabetic retinopathy; GLP-1, glucagon-like peptide-1; HDL-C, high-density lipoprotein cholesterol; LDL-C, low-density lipoprotein cholesterol.

Although hyperglycemia is the main cause of DR, hyperlipidemia is also considered to play a decisive role in its pathogenesis. Triglyceride levels are directly related to the incidence and severity of DR, and long-term lipid-lowering therapy can reduce the need for laser therapy for patients with DR (101). In recent years, an increasing number of studies have investigated lipids in association with diabetes. For DR, an abnormal vascular endothelial function leads to increased plasma exudation, and the lipids themselves aggravate endothelial cell damage (102). In diabetic rat models, the development of DR has been found to be enhanced in a hyperlipidemic environment, and the combination of hyperlipidemia and hyperglycemia enhances the activation of the apoptotic pathway in retinal capillary cells by accelerating mitochondrial damage (103).

Curcumin may also play a direct role in reducing blood glucose levels (Fig. 7). de Melo et al used a randomized controlled experiment to supplement curcumin or placebo for individuals $>18$ years (104). After a 4-week follow-up, they found that compared with the placebo, curcumin supplementation effectively reduced the fasting blood glucose concentration of individuals with a certain degree of blood glucose abnormality, but not that of non-diabetic individuals (104). In mice and rat models of diabetes, curcumin and its synthetic analogs have been found to significantly reduce the level of blood glucose and glycosylated hemoglobin, improve the function of $\beta$ cells, prevent $\beta$ cell death (105-107), reduce insulin resistance, and delay the occurrence and progression of diabetes (108). Moreover, the therapeutic effect of curcumin has been shown to be more prominent when bioavailability enhancers, such as piperine are used (109). Kato et al found curcumin to promote the level of glucagon-like peptide 1 (GLP-1) and to play a hypoglycemic role in a rat model in which curcumin was administered and glucose was then injected intraperitoneally to improve glucose tolerance (110). These findings demonstrate that curcumin has the biological function of promoting GLP-1 secretion, and the curcumin-induced increase in endogenous GLP-1 secretion may reduce the required dosage of other diabetic drugs and help prevent diabetes and related complications (110).

Several studies have also revealed that curcumin is a natural lipid regulator (Fig. 7). In a randomized, placebo-controlled, double-blind trial, half of the patients with metabolic syndrome received curcumin extract capsules for 12 weeks. The results revealed a significant increase in high-density lipoprotein cholesterol (HDL-C) and a significant decrease in low-density lipoprotein cholesterol (LDL-C), accompanied by a significant decrease in triglyceride levels (111). This cholesterol-lowering effect is believed to be related to the upregulation of LDL receptors following the administration of curcumin (112-114). Soni and Kuttan also conducted an experiment on the effect of curcumin administration on the reduction of serum cholesterol and lipid peroxide levels (115). It was found that healthy individuals who received $500 \mathrm{mg}$ of curcumin daily for 7 days also exhibited a decrease in serum lipid peroxide and total cholesterol levels and an increase in HDL-C (115). Of note, in the serum results of New Zealand white rabbits fed a curcumin diet for 8 weeks, Um et al demonstrated that curcumin can indeed reduce the level of total cholesterol and low-density lipoprotein, but it cannot affect the level of high-density 
lipoprotein. The latter may be related to the concomitant cholesterol diet (116). In light of these findings, taken together, it can be concluded that curcumin can reduce blood glucose and blood lipid in many ways, and thus improve the symptoms of diabetes and DR.

\section{Conclusions}

DR represents one of the severe microvascular complications of diabetes mellitus. Its underlying pathogenic mechanisms represent a complex process characterized by multi-factorial participation, multigenic regulation, and multi-step evolutionary processes. A variety of mechanisms jointly contribute to the occurrence and progression of DR. Due to the large number of patients with DR worldwide, particularly individuals of working-age, increasing attention is being paid to DR as a severe eye disease that leads to blindness. It has been found that curcumin can improve glucose and lipid metabolism, improve insulin sensitivity, reduce insulin resistance, and improve oxidative stress and inflammatory pathway conditions in diabetes and DR. In the future, further clinical trials may be designed to assess whether the bioavailability of curcumin could be improved by combining it with other available therapies. The regulatory effects of curcumin on autophagy and apoptosis may provide insight for the development of novel therapeutics for DR. Further studies are required to explore the therapeutic potential of curcumin and evaluate whether it can be used as a novel drug for DR in clinical practice.

\section{Acknowledgements}

Not applicable.

\section{Funding}

This study was supported by the National Natural Science Foundation (81970836), the International Cooperation Project of Science and Technology Department of Jilin Province (20190701044GH), Training Program for Outstanding Young Teachers of Jilin University (419080520313), and the Natural Science Foundation Project of Science and Technology Department of Jilin Province (20200201360JC).

\section{Availability of data and materials}

Not applicable.

\section{Authors' contributions}

JY, XM and FJY were involved in the conception of the study, and in the writing and preparation of the manuscript, as well as in the supervision of figure preparation. JY, JFC and XL were involved in the writing of the manuscript and preparation of the figures. JY, JLF and GFS were involved in the writing and supervision of the manuscript.

\section{Ethics approval and consent to participate}

Not applicable.

\section{Patient consent for publication}

Not applicable.

\section{Competing interests}

The authors declare that they have no competing interests.

\section{References}

1. International Diabetes Federation (IDF): IDF Diabetes Atlas. 8th Edition. IDF, 2017. https://www.diabetesatlas.org/upload/ resources/previous/files/8/IDF_DA_8e-EN-final.pdf.

2. Logue J, Walker JJ, Colhoun HM, Leese GP, Lindsay RS, McKnight JA, Morris AD, Pearson DW, Petrie JR, Philip S, et al: Do men develop type 2 diabetes at lower body mass indices than women? Diabetologia 54: 3003-3006, 2011.

3. Hartwig S, Greiser KH, Medenwald D, Tiller D, Herzog B, Schipf S, Ittermann T, Völzke H, Müller G, Haerting J and Kluttig A: Association of change of anthropometric measurements with incident type 2 diabetes mellitus: A pooled analysis of the prospective population-based CARLA and SHIP cohort studies. Medicine(Baltimore) 94: e1394, 2015.

4. Wannamethee SG, Papacosta O, Lawlor DA, Whincup PH, Lowe GD, Ebrahim S and Sattar N: Do women exhibit greater differences in established and novel risk factors between diabetes and non-diabetes than men? the British regional heart study and British women's heart health study. Diabetologia 55: 80-87, 2012.

5. Shigiyama F, Kumashiro N, Tsuneoka Y, Igarashi H, Yoshikawa F, Kakehi S, Funato H and Hirose T: Mechanisms of sleep deprivation-induced hepatic steatosis and insulin resistance in mice. Am J Physiol Endocrinol Metab 315: E848-E858, 2018.

6. Pan KY, Xu W, Mangialasche F, Fratiglioni L and Wang HX: Work-related psychosocial stress and the risk of type 2 diabetes in later life. J Intern Med 281: 601-610, 2017.

7. Sohn EH, van Dijk HW, Jiao C, Kok PHB, Jeong W, Demirkaya N Garmager A, Wit F, Kucukevcilioglu M, van Velthoven ME, et al: Retinal neurodegeneration may precede microvascular changes characteristic of diabetic retinopathy in diabetes mellitus. Proc Natl Acad Sci USA 113: E2655-E2664, 2016.

8. Sahin K, Orhan C, Tuzcu M, Sahin N, Tastan H, Özercan IH, Güler O, Kahraman N, Kucuk O and Ozpolat B: Chemopreventive and antitumor efficacy of curcumin in a spontaneously developing hen ovarian cancer model. Cancer Prev Res (Phila) 11: 59-67, 2018.

9. Fu H, Wang C, Yang D, Wei Z, Xu J, Hu Z, Zhang Y, Wang W, Yan R and Cai Q: Curcumin regulates proliferation, autophagy, and apoptosis in gastric cancer cells by affecting PI3K and P53 signaling. J Cell Physiol 233: 4634-4642, 2018.

10. Kronski E, Fiori ME, Barbieri O, Astigiano S, Mirisola V, Killian PH, Bruno A, Pagani A, Rovera F, Pfeffer U, et al: miR181b is induced by the chemopreventive polyphenol curcumin and inhibits breast cancer metastasis via down-regulation of the inflammatory cytokines CXCL1 and -2. Mol Oncol 8: 581-595, 2014.

11. Ide H, Lu Y, Noguchi T, Muto S, Okada H, Kawato S and Horie S: Modulation of AKR1C2 by curcumin decreases testosterone production in prostate cancer. Cancer Sci 109: 1230-1238, 2018.

12. Yuan J, Liu R, Ma Y, Zhang Z and Xie Z: Curcumin attenuates airway inflammation and airway remolding by inhibiting NF- $\kappa \mathrm{B}$ signaling and COX-2 in cigarette smoke-induced COPD mice. Inflammation 41: 1804-1814, 2018.

13. Ding XQ, Wu WY, Jiao RQ, Gu TT, Xu Q, Pan Y and Kong LD: Curcumin and allopurinol ameliorate fructose-induced hepatic inflammation in rats via miR-200a-mediated TXNIP/NLRP3 inflammasome inhibition. Pharmacol Res 137: 64-75, 2018.

14. Xiao Y, Xia J, Wu S, Lv Z, Huang S, Huang H, Su X, Cheng J and Ke Y: Curcumin inhibits acute vascular inflammation through the activation of heme oxygenase-1. Oxid Med Cell Longev 2018: 3295807, 2018.

15. Sharma S, Kulkarni SK and Chopra K: Curcumin, the active principle of turmeric (Curcuma longa), ameliorates diabetic nephropathy in rats. Clin Exp Pharmacol Physiol 33: 940-945, 2006.

16. Kadiyala CSR, Zheng L, Du Y, Yohannes E, Kao HY, Miyagi M and Kern TS: Acetylation of retinal histones in diabetes increases inflammatory proteins: Effects of minocycline and manipulation of histone acetyltransferase (HAT) and histone deacetylase (HDAC). J Biol Chem 287: 25869-25880, 2012. 
17. Wang LL, Chen H, Huang $\mathrm{K}$ and Zheng L: Elevated histone acetylations in Müller cells contribute to inflammation: A novel inhibitory effect of minocycline. Glia 60: 1896-1905, 2012.

18. Yun JM, Jialal I and Devaraj S: Epigenetic regulation of high glucose-induced proinflammatory cytokine production in monocytes by curcumin. J Nutr Biochem 22: 450-458, 2011.

19. Gui L, Jiang S, Xie D, Yu L, Huang Y, Zhang Z and Liu Y: Analysis of complete chloroplast genomes of Curcuma and the contribution to phylogeny and adaptive evolution. Gene 732 : $144355,2020$.

20. Nishino H, Tokuda H, Satomi Y, Masuda M, Osaka Y, Yogosawa S, Wada S, Mou XY, Takayasu J, Murakoshi M, et al: Cancer prevention by antioxidants. Biofactors 22: 57-61, 2004.

21. Boyanapalli SSS., Huang Y, Su Z, Cheng D, Zhang C, Guo Y, Rao R, Androulakis IP and Kong AN: Pharmacokinetics and pharmacodynamics of curcumin in regulating anti-inflammatory and epigenetic gene expression. Biopharm Drug Dispos 39: 289-297, 2018.

22. Lao CD, Ruffin MT, Normolle D, Heath DD, Murray SI, Bailey JM, Boggs ME, Crowell J, Rock CL and Brenner DE: Dose escalation of a curcuminoid formulation. BMC Complement Altern Med 6: 10,2006.

23. Falconieri MC, Adamo M, Monasterolo C, Bergonzi MC, Coronnello $\mathrm{M}$ and Bilia AR: New dendrimer-based nanoparticles enhance curcumin solubility. Planta Med 83: 420-425, 2017.

24. Tiyaboonchai W, Tungpradit W and Plianbangchang $\mathrm{P}$. Formulation and characterization of curcuminoids loaded solid lipid nanoparticles. Int J Pharm 337: 299-306, 2007.

25. Wang W, Zhu R, Xie Q, Li A, Xiao Y, Li K, Liu H, Cui D, Chen Y and Wang S: Enhanced bioavailability and efficiency of curcumin for the treatment of asthma by its formulation in solid lipid nanoparticles. Int J Nanomedicine 7: 3667-3677, 2012.

26. Shoba G, Joy D, Joseph T, Majeed M, Rajendran R and Srinivas PS: Influence of piperine on the pharmacokinetics of curcumin in animals and human volunteers. Planta Med 64 353-356, 1998.

27. Skoupa N, Dolezel P, Ruzickova E and Mlejnek P: Apoptosis induced by the curcumin analogue EF-24 is neither mediated by oxidative stress-related mechanisms nor affected by expression of main drug transporters $\mathrm{ABCB} 1$ and $\mathrm{ABCG} 2$ in human leukemia cells. Int J Mol Sci 18: 2289, 2017.

28. Ingelfinger JR and Jarcho JA: Increase in the incidence of diabetes and its implications. N Engl J Med 376: 1473-1474, 2017.

29. Javidi MA, Kaeidi A, Mortazavi Farsani SS, Babashah S and Sadeghizadeh M: Investigating curcumin potential for diabetes cell therapy, in vitro and in vivo study. Life Sci 239: 116908, 2019.

30. Chuengsamarn S, Rattanamongkolgul S, Luechapudiporn R, Phisalaphong $\mathrm{C}$ and Jirawatnotai S: Curcumin extract for prevention of type 2 diabetes. Diabetes Care 35: 2121-2127, 2012.

31. Al-Saud NBS: Impact of curcumin treatment on diabetic albino rats. Saudi J Biol Sci 27: 689-694, 2020.

32. Qihui L, Shuntian D, Xin Z, Xiaoxia Y and Zhongpei C: Protection of curcumin against streptozocin-induced pancreatic cell destruction in T2D rats. Planta Med 86: 113-120, 2020

33. Bulboacă AE, Boarescu PM, Bolboacă SD, Blidaru M, Festilă D, Dogaru $\mathrm{G}$ and Nicula CA: Comparative effect of curcumin versus liposomal curcumin on systemic pro-inflammatory cytokines profile, MCP-1 and RANTES in experimental diabetes mellitus. Int J Nanomedicine 14: 8961-8972, 2019.

34. Li J, Wu N, Chen X, Chen H, Yang X and Liu C: Curcumin protects islet cells from glucolipotoxicity by inhibiting oxidative stress and NADPH oxidase activity both in vitro and in vivo. Islets 11: 152-164, 2019.

35. Xia ZH, Jiang X, Li K, Li LX, Chen WB, Wang YX and Liu YQ: Curcumin inhibits alloxan-induced pancreatic islet cell damage via antioxidation and antiapoptosis. J Biochem Mol Toxicol 34 e22499, 2020.

36. Gupta A, Tripathi AK, Tripathi RL, Madhu SV and Banerjee BD: Advanced glycosylated end products-mediated activation of polymorphonuclear neutrophils in diabetes mellitus and associated oxidative stress. Indian J Biochem Biophys 44: 373-378, 2007.

37. Aplin AC, Gelati M, Fogel E, Carnevale E and Nicosia RF: Angiopoietin-1 and vascular endothelial growth factor induce expression of inflammatory cytokines before angiogenesis. Physiol Genomics 27: 20-28, 2006.

38. Kowluru RA and Kanwar M: Effects of curcumin on retinal oxidative stress and inflammation in diabetes. Nutr Metab (Lond) 4: 8, 2007.
39. Assis RP, Arcaro CA, Gutierres VO, Oliveira JO, Costa PI, Baviera AM and Brunetti IL: Combined effects of curcumin and lycopene or bixin in yoghurt on inhibition of LDL oxidation and increases in HDL and paraoxonase levels in streptozotocin-diabetic rats. Int J Mol Sci 18: 332, 2017.

40. Gutierres VO, Pinheiro CM, Assis RP, Vendramini RC, Pepato MT and Brunetti IL: Curcumin-supplemented yoghurt improves physiological and biochemical markers of experimental diabetes. Br J Nutr 108: 440-448, 2012.

41. Jiménez-Osorio AS, González-Reyes S and Pedraza-Chaverri J: Natural Nrf2 activators in diabetes. Clin Chim Acta 448: 182-192, 2015.

42. Zuo ZF, Zhang Q and Liu XZ: Protective effects of curcumin on retinal Müller cell in early diabetic rats. Int J Ophthalmol 6: 422-424, 2013

43. Liu Z, Lin H, Ye S, Liu QY, Meng Z, Zhang CM, Xia Y, Margoliash E, Rao Z and Liu XJ: Remarkably high activities of testicular cytochrome $\mathrm{c}$ in destroying reactive oxygen species and in triggering apoptosis. Proc Natl Acad Sci USA 103: 8965-8970, 2006.

44. Maugeri A, Mazzone MG, Giuliano F, Vinciguerra M, Basile G, Barchitta M and Agodi A: Curcumin modulates DNA methyltransferase functions in a cellular model of diabetic retinopathy. Oxid Med Cell Longev 2018: 5407482, 2018

45. Shishodia S, Sethi G and Aggarwal BB: Curcumin: Getting back to the roots. Ann N Y Acad Sci 1056: 206-217, 2005.

46. Chen Y, Li C, Duan S, Yuan X, Liang J and Hou S: Curcumin attenuates potassium oxonate-induced hyperuricemia and kidney inflammation in mice. Biomed Pharmacother 118: 109195, 2019.

47. Balasubramanyam M, Koteswari AA, Kumar RS, Monickaraj SF Maheswari JU and Mohan V: Curcumin-induced inhibition of cellular reactive oxygen species generation: Novel therapeutic implications. J Biosci 28: 715-721, 2003.

48. Yang F, Yu J, Ke F, Lan M, Li D, Tan K, Ling J, Wang Y, Wu K and $\mathrm{Li} \mathrm{D}$ : Curcumin alleviates diabetic retinopathy in experimental diabetic rats. Ophthalmic Res 60: 43-54, 2018.

49. Bulboacă AE, Porfire AS, Tefas LR, Boarescu PM, Bolboacă SD, Stănescu IC, Bulboacă AC and Dogaru G: Liposomal curcumin is better than curcumin to alleviate complications in experimental diabetic mellitus. Molecules 24: 846, 2019.

50. Zhou P, Xie W, Meng X, Zhai Y, Dong X, Zhang X, Sun G and Sun X: Notoginsenoside R1 ameliorates diabetic retinopathy through PINK1-dependent activation of mitophagy. Cells 8: 213 , 2019.

51. Brucklacher RM, Patel KM, VanGuilder HD, Bixler GV Barber AJ, Antonetti DA, Lin CM, LaNoue KF, Gardner TW, Bronson SK and Freeman WM: Whole genome assessment of the retinal response to diabetes reveals a progressive neurovascular inflammatory response. BMC Med Genomics 1: 26, 2008.

52. Yuuki T, Kanda T, Kimura Y, Kotajima N, Tamura J, Kobayashi I and Kishi S: Inflammatory cytokines in vitreous fluid and serum of patients with diabetic vitreoretinopathy. J Diabetes Complications 15: 257-259, 2001.

53. Joussen AM, Murata T, Tsujikawa A, Kirchhof B, Bursell SE and Adamis AP: Leukocyte-mediated endothelial cell injury and death in the diabetic retina. Am J Pathol 158: 147-152, 2001.

54. Khalfaoui T, Lizard G and Ouertani-Meddeb A: Adhesion molecules (ICAM-1 and VCAM-1) and diabetic retinopathy in type 2 diabetes. J Mol Histol 39: 243-249, 2008.

55. Boss JD, Singh PK, Pandya HK, Tosi J, Kim C, Tewari A, Juzych MS, Abrams GW and Kumar A: Assessment of neurotrophins and inflammatory mediators in vitreous of patients with diabetic retinopathy. Invest Ophthalmol Vis Sci 58: 5594-5603, 2017.

56. Luo DW, Zheng Z, Wang H, Fan Y, Chen F, Sun Y, Wang WJ, Sun $T$ and Xu X: UPP mediated diabetic retinopathy via ROS/PARP and NF- $\kappa$ B inflammatory factor pathways. Curr Mol Med 15: 790-799, 2015.

57. Hollanders K, Van Hove I, Sergeys J, Van Bergen T, Lefevere E, Kindt N, Castermans K, Vandewalle E, van Pelt J, Moons L and Stalmans I: AMA0428, a potent rock inhibitor, attenuates early and late experimental diabetic retinopathy. Curr Eye Res 42: 260-272, 2017.

58. Ran Z, Zhang Y, Wen X and Ma J: Curcumin inhibits high glucose induced inflammatory injury in human retinal pigment epithelial cells through the ROS PI3K/AKT/mTOR signaling pathway. Mol Med Rep 19: 1024-1031, 2019.

59. Costagliola C, Romano V, De Tollis M, Aceto F, dell'Omo R, Romano MR, Pedicino C and Semeraro F: TNF-alpha levels in tears: A novel biomarker to assess the degree of diabetic retinopathy. Mediators Inflamm 2013: 629529, 2013. 
60. Gupta SK, Kumar B, Nag TC, Agrawal SS, Agrawal R, Agrawal P, Saxena R and Srivastava S: Curcumin prevents experimental diabetic retinopathy in rats through its hypoglycemic, antioxidant, and anti-inflammatory mechanisms. J Ocul Pharmacol Ther 27: 123-130, 2011.

61. Jiang C, Ting AT and Seed B: PPAR-gamma agonists inhibit production of monocyte inflammatory cytokines. Nature 391: 82-86, 1998.

62. Charrier A, Wang L, Stephenson EJ, Ghanta SV, Ko CW, Croniger CM, Bridges D and Buchner DA: Zinc finger protein 407 overexpression upregulates PPAR target gene expression and improves glucose homeostasis in mice. Am J Physiol Endocrinol Metab 311: E869-E880, 2016.

63. Aljada A, Garg R, Ghanim H, Mohanty P, Hamouda W, Assian E and Dandona P: Nuclear factor-kappaB suppressive and inhibitor-kappaB stimulatory effects of troglitazone in obese patients with type 2 diabetes: Evidence of an antiinflammatory action? J Clin Endocrinol Metab 86: 3250-3256, 2001.

64. Haffner SM, Greenberg AS, Weston WM, Chen H, Williams K and Freed MI: Effect of rosiglitazone treatment on nontraditional markers of cardiovascular disease in patients with type 2 diabetes mellitus. Circulation 106: 679-684, 2002.

65. Shafabakhsh R, Mobini M, Raygan F, Aghadavod E, Ostadmohammadi V, Amirani E, Mansournia MA and Asemi Z: Curcumin administration and the effects on psychological status and markers of inflammation and oxidative damage in patients with type 2 diabetes and coronary heart disease. Clin Nutr ESPEN 40: 77-82, 2020.

66. Li HY, Yang M, Li Z and Meng Z: Curcumin inhibits angiotensin II-induced inflammation and proliferation of rat vascular smooth muscle cells by elevating PPAR- $\gamma$ activity and reducing oxidative stress. Int J Mol Med 39: 1307-1316, 2017.

67. Yun JH, Park SW, Kim KJ, Bae JS, Lee EH, Paek SH, Kim SU, Ye S, Kim JH and Cho CH: Endothelial STAT3 activation increases vascular leakage through downregulating tight junction proteins: Implications for diabetic retinopathy. J Cell Physiol 232: 1123-1134, 2017.

68. Shibuya M: Vascular endothelial growth factor and its receptor system: Physiological functions in angiogenesis and pathological roles in various diseases. J Biochem 153, 13-19, 2013.

69. Miyamoto K, Khosrof S, Bursell SE, Rohan R, Murata T, Clermont AC, Aiello LP, Ogura Y and Adamis AP: Prevention of leukostasis and vascular leakage in streptozotocin-induced diabetic retinopathy via intercellular adhesion molecule-1 inhibition. Proc Natl Acad Sci USA 96: 10836-10841, 1999.

70. Mrudula T, Suryanarayana P, Srinivas PNBS and Reddy GB: Effect of curcumin on hyperglycemia-induced vascular endothelial growth factor expression in streptozotocin-induced diabetic rat retina. Biochem Biophys Res Commun 361: 528-532, 2007

71. Li J, Wang P, Ying J, Chen Z and Yu S: Curcumin attenuates retinal vascular leakage by inhibiting calcium/calmodulin-dependent protein kinase II activity in streptozotocin-induced diabetes. Cel Physiol Biochem 39: 1196-1208, 2016.

72. Pradhan D, Dasmohapatra T and Tripathy G: Pharmacognostic evaluation of curcumin on diabetic retinopathy in alloxan-induced diabetes through NF-KB and Brn3a related mechanism. Pharmacogn J 10: 324-332, 2018.

73. Khimmaktong W, Petpiboolthai H, Sriya P and Anupunpisit V: Effects of curcumin on restoration and improvement of microvasculature characteristic in diabetic rat's choroid of eye. J Med Assoc Thai 97 (Suppl 2): S39-S46, 2014.

74. Lee TK, Park JY, Yu JS, Jang TS, Oh ST, Pang C, Ko YJ, Kang KS and Kim KH: 7 $\alpha, 15$-Dihydroxydehydroabietic acid from Pinus koraiensis inhibits the promotion of angiogenesis through downregulation of VEGF, p-Akt and p-ERK in HUVECs. Bioorg Med Chem Lett 28: 1084-1089, 2018.

75. Farajipour $\mathrm{H}$, Rahimian $\mathrm{S}$ and Taghizadeh M: Curcumin: A new candidate for retinal disease therapy? J Cell Biochem 2018 (Epub ahead of print)

76. Ran Z, Zhang Y, Wen X and Ma J: Curcumin inhibits high glucose induced inflammatory injury in human retinal pigment epithelial cells through the ROS PI3K/AKT/mTOR signaling pathway. Mol Med Rep 19: 1024-1031, 2019.

77. Okamoto T, Yamagishi SI, Inagaki Y, Amano S, Koga K, Abe R, Takeuchi M, Ohno S, Yoshimura A and Makita Z: Angiogenesis induced by advanced glycation end products and its prevention by cerivastatin. FASEB J 16: 1928-1930, 2002.
78. Salvucci O, Basik M, Yao L, Bianchi R and Tosato G: Evidence for the involvement of SDF-1 and CXCR4 in the disruption of endothelial cell-branching morphogenesis and angiogenesis by TNF-alpha and IFN-gamma. J Leukoc Biol 76: 217-226, 2004.

79. Butler JM, Guthrie SM, Koc M, Afzal A, Caballero S, Brooks HL, Mames RN, Segal MS, Grant MB and Scott EW: SDF-1 is both necessary and sufficient to promote proliferative retinopathy. J Clin Invest 115: 86-93, 2005.

80. Arbiser JL, Klauber N, Rohan R, van Leeuwen R, Huang MT, Fisher C, Flynn E and Byers HR: Curcumin is an in vivo inhibitor of angiogenesis. Mol Med 4: 376-383, 1998.

81. Sameermahmood Z, Balasubramanyam M, Saravanan T and Rema M: Curcumin modulates SDF-1alpha/CXCR4-induced migration of human retinal endothelial cells (HRECs). Invest Ophthalmol Vis Sci 49: 3305-3311, 2008

82. Salven P, Hattori K, Heissig B and Rafii S: Interleukin-1alpha promotes angiogenesis in vivo via VEGFR-2 pathway by inducing inflammatory cell VEGF synthesis and secretion. FASEB J 16: $1471-1473,2002$

83. Mohammad G and Kowluru RA: Novel role of mitochondrial matrix metalloproteinase- 2 in the development of diabetic retinopathy. Invest Ophthalmol Vis Sci 52: 3832-3841, 2011.

84. Mohammad G and Kowluru RA: Matrix metalloproteinase-2 in the development of diabetic retinopathy and mitochondrial dysfunction. Lab Invest 90: 1365-1372, 2010.

85. Fu Y, Wang Y, Gao X, Li H and Yuan Y: Dynamic expression of HDAC3 in $\mathrm{db} / \mathrm{db}$ mouse RGCs and its relationship with apoptosis and autophagy. J Diabetes Res 2020: 6086780, 2020.

86. Zhang X, He N, Xing Y and Lu Y: Knockdown of GCN2 inhibits high glucose-induced oxidative stress and apoptosis in retinal pigment epithelial cells. Clin Exp Pharmacol Physiol 47: 591-598, 2020.

87. Mathew R and White E: Why sick cells produce tumors: The protective role of autophagy. Autophagy 3: 502-505, 2007.

88. Hara T, Nakamura K, Matsui M, Yamamoto A, Nakahara Y, Suzuki-Migishima R, Yokoyama M, Mishima K, Saito I, Okano $\mathrm{H}$ and Mizushima N: Suppression of basal autophagy in neural cells causes neurodegenerative disease in mice. Nature 441: 885-889, 2006

89. Pahari S, Negi S, Aqdas M, Arnett E, Schlesinger LS and Agrewala JN: Induction of autophagy through CLEC4E in combination with TLR4: An innovative strategy to restrict the survival of mycobacterium tuberculosis. Autophagy 16: 1021-1043, 2020.

90. Fernández ÁF, Sebti S, Wei Y, Zou Z, Shi M, McMillan KL, He C, Ting T, Liu Y, Chiang WC, et al: Disruption of the beclin 1-BCL2 autophagy regulatory complex promotes longevity in mice. Nature 558: 136-140, 2018

91. Luo Y, Dong X, Lu S, Gao Y, Sun G and Sun X: Gypenoside XVII alleviates early diabetic retinopathy by regulating Müller cell apoptosis and autophagy in $\mathrm{db} / \mathrm{db}$ mice. Eur J Pharmacol 895: 173893,2021

92. de Faria JML, Duarte DA, Montemurro C, Papadimitriou A, Consonni SR and de Faria JBL: Defective autophagy in diabetic retinopathy. Invest Ophthalmol Vis Sci 57: 4356-4366, 2016.

93. Pereira C: Crosstalk between endoplasmic reticulum stress and protein misfolding in neurodegenerative diseases. ISRN Cell Biol 2013: 2013.

94. Pittalà V,Fidilio A, Lazzara F, Platania CBM, Salerno L, Foresti R, Drago $\mathrm{F}$ and Bucolo C: Effects of novel nitric oxide-releasing molecules against oxidative stress on retinal pigmented epithelial cells. Oxid Med Cell Longev 2017: 1420892, 2017.

95. Bucolo C, Drago F, Maisto R, Romano GL, D'Agata V, Maugeri $G$ and Giunta $S$ : Curcumin prevents high glucose damage in retinal pigment epithelial cells through ERK1/2-mediated activation of the Nrf2/HO-1 pathway. J Cell Physiol 234: 17295-17304, 2019.

96. Chen W, Zou P, Zhao Z, Weng Q, Chen X, Ying S, Ye Q, Wang Z, Ji J and Liang G: Selective killing of gastric cancer cells by a small molecule via targeting TrxR1 and ROS-mediated ER stress activation. Oncotarget 7: 16593-16609, 2016.

97. Ye M, Qiu H, Cao Y, Zhang M, Mi Y, Yu J and Wang C: Curcumin improves palmitate-induced insulin resistance in human umbilical vein endothelial cells by maintaining proteostasis in endoplasmic reticulum. Front Pharmacol 8: 148, 2017.

98. Zhang P, Fang J, Zhang J, Ding S and Gan D: Curcumin inhibited podocyte cell apoptosis and accelerated cell autophagy in diabetic nephropathy via regulating beclin1/UVRAG/Bcl2 . Diabetes Metab Syndr Obes 13: 641-652, 2020. 
99. Yao Q, Ke ZQ, Guo S, Yang XS, Zhang FX, Liu XF, Chen X, Chen HG, Ke HY and Liu C: Curcumin protects against diabetic cardiomyopathy by promoting autophagy and alleviating apoptosis. J Mol Cell Cardiol 124: 26-34, 2018.

100. Gürler B, Vural H, Yilmaz N, Oguz H, Satici A and Aksoy N: The role of oxidative stress in diabetic retinopathy. Eye (Lond) 5: 730-735, 2000.

101. Chew EY, Klein ML, Ferris FL III, Remaley NA, Murphy RP, Chantry K, Hoogwerf BJ and Miller D: Association of elevated serum lipid levels with retinal hard exudate in diabetic retinopathy. Early treatment diabetic retinopathy study (ETDRS) report 22. Arch Ophthalmol 114: 1079-1084, 1996.

102. Kumar B, Kowluru A and Kowluru RA: Lipotoxicity augments glucotoxicity-induced mitochondrial damage in the development of diabetic retinopathy. Invest Ophthalmol Vis Sci 56: 2985-2995, 2015

103. Kowluru RA, Mishra M, Kowluru A and Kumar B: Hyperlipidemia and the development of diabetic retinopathy: Comparison between type 1 and type 2 animal models. Metabolism 65: 1570-1581, 2016.

104. de Melo ISV, Dos Santos AF and Bueno NB: Curcumin or combined curcuminoids are effective in lowering the fasting blood glucose concentrations of individuals with dysglycemia: Systematic review and meta-analysis of randomized controlled trials. Pharmacol Res 128: 137-144, 2018.

105. Seo KI, Choi MS, Jung UJ, Kim HJ, Yeo J, Jeon SM and Lee MK Effect of curcumin supplementation on blood glucose, plasma insulin, and glucose homeostasis related enzyme activities in diabetic db/db mice. Mol Nutr Food Res 52: 995-1004, 2008.

106. Das KK, Razzaghi-Asl N, Tikare SN, Di Santo R, Costi R, Messore A, Pescatori L, Crucitti GC, Jargar JG, Dhundasi SA and Saso L: Hypoglycemic activity of curcumin synthetic analogues in alloxan-induced diabetic rats. J Enzyme Inhib Med Chem 31: 99-105, 2016.

107. Kaur G, Invally $M$ and Chintamaneni M: Influence of piperine and quercetin on antidiabetic potential of curcumin. J Complement Integr Med 13: 247-255, 2016.
108. Song Z, Wang H, Zhu L, Han M, Gao Y, Du Y and Wen Y: Curcumin improves high glucose-induced INS-1 cell insulin resistance via activation of insulin signaling. Food Funct 6 : 461-469, 2015

109. Pivari F, Mingione A, Brasacchio C and Soldati L: Curcumin and type 2 diabetes mellitus: Prevention and treatment. Nutrients 11: $1837,2019$.

110. Kato M, Nishikawa S, Ikehata A, Dochi K, Tani T, Takahashi T, Imaizumi A and Tsuda T: Curcumin improves glucose tolerance via stimulation of glucagon-like peptide-1 secretion. Mol Nutr Food Res 61: 2017.

111. Yang YS, Su YF, Yang HW, Lee YH, Chou JI and Ueng KC: Lipid-lowering effects of curcumin in patients with metabolic syndrome: A randomized, double-blind, placebo-controlled trial. Phytother Res 28: 1770-1777, 2014.

112. Peschel D, Koerting R and Nass N: Curcumin induces changes in expression of genes involved in cholesterol homeostasis. J Nutr Biochem 18: 113-119, 2007.

113. Dou X, Fan C, Wo L, Yan J, Qian Y and Wo X: Curcumin up-regulates LDL receptor expression via the sterol regulatory element pathway in HepG2 cells. Planta Med 74: 1374-1379, 2008.

114. Fan C, Qian Y, Wo X, Yan J and Gao L: Effect of curcumin on the gene expression of low density lipoprotein receptors. Chin J Integr Med 11: 201-204, 2005 (In Chinese).

115. Soni KB and Kuttan R: Effect of oral curcumin administration on serum peroxides and cholesterol levels in human volunteers. Indian J Physiol Pharmacol 36: 273-275, 1992.

116. Um MY, Hwang KH, Choi WH, Ahn J, Jung CH and Ha TY: Curcumin attenuates adhesion molecules and matrix metalloproteinase expression in hypercholesterolemic rabbits. Nutr Res 34: 886-893, 2014.

This work is licensed under a Creative Commons Attribution-NonCommercial-NoDerivatives 4.0 International (CC BY-NC-ND 4.0) License. 